\title{
Research of China High Education Exam Form
}

\author{
Mingqi Wu \\ Tourism College of Dalian University, China \\ email : wlwhxf1030-1@outlook.com
}

Keywords: High education, Exam form, Exam reform.

\begin{abstract}
So far, exam form in universities in China have been unilateral, exam is mainly to check students' knowledge and memory. It is not conducive to innovative talent training. Exam forms consist in many problems, whereby engendering education side-effect. Exam form must be reformed in a bid to fit in with the trend of time. It is practical to find problems and raise some fundamental suggestions, combining with the situation of current exam form in China so that reform of exam form can be improved in China.
\end{abstract}

\section{Introduction}

Talent training of high education involves laying program of talent training, setting curriculum system, teaching content, teaching method and so forth. Exam Form is positive for the talent training, which encompass closed-book exam, open-book exam, paper, literature review and etc. At present, many scholars give opinions and suggestions for exam reform of high education, not to mention that many universities and colleges also take exam very seriously. But many exam reforms are still progressing in the phase of theory research and they are also deemed to be devoid of the specific practices. This paper finds strategies of exam form of high education from a series of existing problems of exam reforms of high education.

\section{Common Several Kinds of Exam Forms of High Education in China}

With reform of high education taking place in China, high education in China enters unprecedentedly fast development period. High education turns from elite education to mass education. So far, high education in China has been staying from quantitative change to qualitative change at the critical period. With the transition from the exam-oriented quality to the quality-oriented education, exam form reform of high education is inevitably imperative. In recent years, many colleges and universities also try some new exam forms, now exam forms of high education have the following kinds:

Final Exam Paper Decides Life. Final exam can decide life. That is summative exam. This method can be also divided into two categories: (1) Final exam paper decides result. If students pass an exam, this outcome will then relieve students of progression anxiety. Otherwise, the students fail in the exam. This kind of exam form is the main fashion adopted by a host of curriculums. (2) Mid-term exam results + final exam results, alternatively, mid-term exam results + final exam results + everyday results, although this kind of form includes mid-term results and everyday results, finally the final exam results is regarded as the main exam results. The final exam result weighs $70 \%$ of total results, even up to $80 \%-90 \%$. In fact, the summative exam is essentially decisive to some extent. Nevertheless, this kind of exam form is passably beneficial to students in some way, which can create students with high scores, but poor ability thereby greatly frustrating students' positivity.

Final Exam Paper Decides Half-life. With improvement of quality education and implementation of new curriculum reform, stereotyped exam form and content are increasingly maladaptive for request of commenting on students' knowledge, capability and quality. Exam form of final exam paper deciding life is criticized by people increasing in a large scale. Progressive as exam reforms are, exam-oriented education existing in China for a few thousand years is entrenched. Exam forms of final exam paper deciding half-life emerge following the transition of era. Final exam paper 
which can decide half-life is an ingenious form. This form puts emphasis on the students' everyday results, which can occupy from $30 \%$ to $50 \%$ of the total marks. They also can help the students to increase their learning motivation because the students are unable to get high score for the final exam papers.

Open-book Exam. Open-book exam can help to train students' ability of collecting and processing information, analyzing questions and solving problems. It can help to reduce students' pressure of the exams and psychology of fear. Now the open-book exams are used for the exam of understanding curriculum.

Oral Exam. Exam teachers direct oral exams that comprises of two steps. Firstly, examinee makes a speech concerning the topic. Secondly, the teacher raises the questions that they have prepared at any time. The teacher can give examinee necessary guidance so that examinee can play as usual. In all, oral exam can test many aspects of examinee such as the oral expression, reaction, psychological quality, appearance and manner.

Paper or Literature Review. In order to let the university students catch up with the step of time, writing paper or literature review is popular in university. Also, writing paper requires looking up plenty of references. This form can make students master the methods of looking up materials and processing information so as to stimulate students' learning motivation. Such, self-study ability of students can be enhanced.

\section{Existing Problems of High Education Exam Forms in China}

Though, exam forms of colleges and universities in China have been reformed. However, they still consist in many problems, limitation of exams make negative influences on education. These influences consisting of teachers' instructing and students' learning not only fails to promote students' comprehensive development, but also seriously hinder students' personality development, impeding training of talent ability and improvement of talent quality. The main aspects can be demonstrated as followings:

Vague Purpose of Exam. Education Glossary consider that exam is a kind of method which is used to examine and evaluate students' academic achievement. Western Education Glossary also reckons that exam can formally evaluate students' learning. That is to say, exam is an inseparable part of teaching activity. It is meaningful for increasing teaching quality. So purpose of exam should be presented as followings: Exam serves for increasing teaching quality, training students' exam-oriented education and flexibility capacity. Also, the content of exams can cultivate students to explain, judge, select, analyze and reason comprehensively. Exam can boost and train students' cognitive ability and practice ability. But people have already formed a trend that exam signifies the end of one curriculum or a period of teaching. Termination of exams and declared exam results are normal procedures and students expect to pass exam. It seems that exam is to let students get decent grades. In accordance with this psychological tendency, purpose of exam becomes increasingly unclear. Now exam emphasizes evaluation as well as selection, but neglect scrutiny, education, stimulation and innovation such that we can obviously draw a conclusion that exam does not encourage students efficiently.

Exam Mislead Learning. Exam undertakes responsibility of differentiating talents, selecting talents, so exam becomes the direction of education in colleges and universities. Under present exam form, learning is understood to learn knowledge of textbook, accept content given by teachers. High score means good learning while low score means poor learning such that the result is that teacher adopt duck-stuffing type of teaching for teaching achievement. Students get tired of learning. Exam becomes the heavy burden of students, they always play passive roles in learning.

Bruise Students' Learning Enthusiasm. Education in China has developed up to now. Colleges and Universities education focus on students ' innovation consciousness and increasing ability. Some students never come to class for a curriculum from the beginning to the end, but they can get higher distinction in academic outcomes. Many people think that it is difficult to find a better job after 
receiving high education due to influence of market economy, all kinds of phenomenon seriously bruise students' learning enthusiasm.

Exam Form Fails to Cater to Development of Time. With the development of nation and society, exam is staying in the changing period. Under present exam form, cultured talent usually lack creativity, creative quality and ability, phenomenon of controlling talent and cultured mediocre person is very serious. Under exam-oriented education, cultured talent can be maladaptive development of time, hindering raising of talent ability and talent quality.

\section{Suggestions of Exam Reform}

High education should pay attention to training innovative ability and practical ability of university students increasing human quality and scientific quality. To check book-knowledge becomes fundamental imperative of traditional exam. To check ability of students is to check understanding, memory and judgment of students. As a matter of fact, to solve life practical problems, innovation ability and exploring spirit are always neglected so that reform of exam form can be irresistible trend.

Focus on Learning Ability of Students. Concept of talent training in colleges and universities should turn from exam-oriented education to quality-oriented education, from concentrating on knowledgable education to strengthening ability training. Final aim of education is learning to learn. First of all, exam is to examine students' learning ability, instead of memory, learning to learn can make students benefit a lot in the future, adapting students to the developmnet of time. Students should learn a set of learning methods. Though students never have access to the knowledge, they can also learn. Exam need focus on learning ability of students.

Emphasize on Innovation Ability of Students. Innovation talent training requests exam forms in universities to have challenge and competitiveness, the exam forms can stimulate students' innovation consciousness and innovation enthusiasm. In the process of comment of whole curriculum, teachers should encourage students to think independently and train students' innovation thinking. Exam content should check students' knowledge, ability and quality. It is very important to handle the relation dialectically between traditional function and innovative function. As result, exam function can be fully realized so that teaching quality can also be raised.

Focus on Students' All-round Development. Exam should reflect human all-round development. Teachers should scientifically use exam methods, making exam improve education processes. Exam forms can reflect students' subject accomplishment, fundamental scientific spirit and scientific attitude. Students' ability of collecting information, finding problems and solving problems can be improved through exams. In a word, exam should focus on students' development wholeheartedly.

Adopt Various Exam Forms. Ideas relating to reforming exam forms and exam regulation must be changed in order to scientifically accomplish exam forms. Unilateral exam form makes exam achievement random. It is detrimental to check students' knowledge and quality. At present, closed-book exams in universities in China occupy a large proportion, while open-book exams occupy a few. Comparatively, theory exam occupies a lot as well, operation exam occupies a few. Teachers should select exam form according to specific subject and characteristic of curriculum. Teaching Free can revert to university in a bid to get Teaching Free right. Teachers' initiative, enthusiasm and innovation can be promoted greatly, pattern of rich and varied talent training can be explored.

\section{References}

[1] Yihong, Strengthen Education Reform, Raise Talent Training Quality [J] China High Education, 2007 (2) 43-45

[2] Zhang Jinbiao, Shaolu, In Relation to Progressing Several Suggestions of Exam Reform in High Universities [J] Education Exploration, 2007 (12) 39-40. 
[3] Shang Xiaoling, Exam Method Reform and innovation research [J] Scientific and Technological Information, 2007 (4) 49-50.

[4] Yang Yongbo, Tang Hongmei, Critical Issues of Education Reform in Universities [J] Scientific and Technological Information, 2007 (16) 513-514.

[5] Zu Liuging, Exam Form Reform and Practice Explore of Curriculum [J] Teaching and Management, 2006 (30) 64-65.

[6] Zhu Zunhong, Necessity of Exam Reform and Suggestions of Reform in Universities in China [J] Economist, 2005 (10) 102-103.

[7] Shi Junfang, Research of High Education Exam Regulation of Talent Training [J] Education and Examination, 2012 (6) 34-35. 